\title{
Resistance to drainage of cerebrospinal fluid: clinical measurement and significance ${ }^{1}$
}

\author{
ALBERT N. MARTINS ${ }^{2}$ \\ From the Neurosurgery Service, Wilford Hall USAF Medical Center, San Antonio, Texas, U.S.A.
}

SUMMARY By infusing saline intrathecally at a constant rate until a new steady-state cerebrospinal fluid (CSF) pressure is attained, one can estimate clinically the apparent resistance ( $\mathrm{Ra})$ to drainage of CSF in $\mathrm{mm}$ saline $/ \mathrm{ml}$./minute. This intrathecal saline infusion test (ITSIT) was performed 36 times on 29 patients with diverse intracranial problems, and the results were analysed and, in most cases, compared with the pneumoencephalogram and the isotope cisternogram. The ITSIT is a safe, simple test to estimate $\mathrm{Ra}$, but factors which are difficult to control (occult leaks from the subarachnoid space; independent fluctuations of CSF pressure) limit its reliability and clinical usefulness. If closely correlated with the clinical syndrome, the pneumoencephalogram, and the isotope cisternogram, an ITSIT may identify decisively the patient who needs a shunt. In addition the ITSIT offers another method by which to investigate the pathophysiological mechanisms of the various states of intracranial hypertension. Results from the test performed on four patients with intracranial hypertension of unknown cause (pseudotumor cerebri) suggest that the underlying mechanism in this condition is probably an impediment to normal CSF drainage.

To improve their ability to identify those patients with enlarged ventricles who would benefit from a shunt, Katzman and Hussey (1970) devised a simple constant-infusion manometric test to estimate 'cerebrospinal fluid (CSF) absorptive ability'. An extension of a method first described in 1948 by Foldes and Arrowood, the intrathecal saline infusion test (ITSIT) of Katzman and Hussey is performed by infusing saline intrathecally at a constant rate until a new steady-state CSF pressure is reached. They found that at an arbitrarily chosen infusion rate of $0.76 \mathrm{ml}$./minute the CSF pressure does not rise above $300 \mathrm{~mm}$ saline in normal subjects. However, at the same infusion rate in patients with an impediment to CSF drainage, the pressure stabilizes at a higher level or even continues to rise until the infusion must be stopped before a steady-state pressure is reached. They concluded that the ITSIT helped them to identify patients who would benefit from a shunt (Hussey, Schanzer, and Katzman, 1970).

1 Presented to the meeting of the American Association of Neurological Surgeons, Boston, April 1972.

2 Present address: Neurosurgery Service, Walter Reed General Hospital, Washington, D.C. 20012, U.S.A.
This report of additional experience with the ITSIT helps to clarify its role in current clinical practice.

\section{METHOD}

The test was performed essentially as described by Katzman and Hussey (1970), except that sedation was usually unnecessary. Briefly, the procedure begins with a routine lumbar puncture performed with an 18 gauge needle. The patient remains in the lateral decubitus with the mid-sagittal plane of his neuraxis horizontal. The CSF pressure is recorded after a 15 minute stabilization period, and the intrathecal saline infusion is begun. A Harvard pump, previously calibrated, infuses $0.9 \%$ sodium chloride solution (prepared for intravenous use) at a constant rate of $0.76 \mathrm{ml} . /$ minute, and measurements of the CSF pressure are made every one to five minutes. The infusion is stopped when a new steady-state pressure is reached, or when the CSF pressure rises above $800 \mathrm{~mm}$ saline.

At the end of the ITSIT in 25 patients, the CSF pressure is returned to the opening level, and through the same lumbar puncture needle $100 \mathrm{mC}$ of high specific activity radioactive iodinated human serum albumin (RISA) is injected intrathecally for subsequent routine cisternography. 

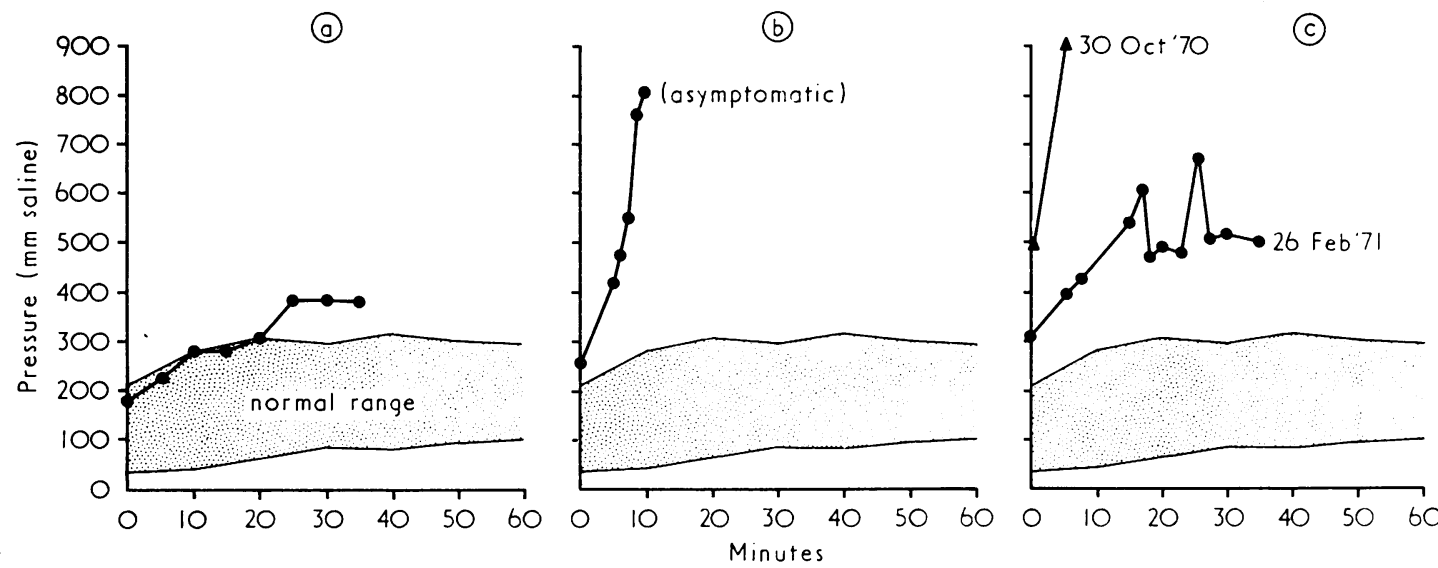

FIG. 1. Examples of pressure versus time curves for three patients: (a) communicating hydrocephalus. (b) $\overrightarrow{\vec{\omega}}$ Cryptococcal meningitis. (c) Occlusion right jugular vein with Secondary ICH. CSF pressure response to a continuous intrathecal saline infusion at $0.76 \mathrm{ml} . /$ minute. Range of normal is from Katzman and Hussey (1970).

\section{DATA ANALYSIS}

Pressure recordings were plotted against time and these curves compared with the range of normal established by Katzman and Hussey (1970) (Fig. 1). The same data were used also to calculate resistance to CSF drainage.

Pappenheimer, Heisey, Jordan, and Downer (1962) and Davson, Hollingsworth, and Segal (1970) have proposed that the normal flow of CSF from the subarachnoid space-that is, drainage-follows Poisueille's law:

$$
\text { Flow }=\frac{\text { Pressure gradient }}{\text { Resistance }} \quad \begin{gathered}
\text { (CSFessure-dural } \\
\text { sinus pressure })
\end{gathered}
$$

If this is accepted then the slope of change in pressure gradient $(\Delta \mathrm{P})$ versus change in flow or drainage rate $(\triangle Q)$ is a measure of resistance $(\mathrm{R})$ to CSF drainage (Davson et al., 1970):

$$
\mathrm{R}=\frac{\Delta \mathrm{P}}{\Delta \mathrm{Q}}
$$

To calculate $\mathbf{R}$ from the ITSIT results, the change in pressure (new steady-state pressure-opening pressure) is divided by the change in drainage rate, which in this series was $0.76 \mathrm{ml}$./minute; $R$ is recorded as $\mathrm{mm}$ saline $/ \mathrm{ml} . /$ minute. These data can be plotted on a graph and the slope of $\Delta \mathrm{P}$ versus $\Delta \mathrm{Q}$ compared with normals. At the steady-state opening pressure, $Q$ is assumed to be $0.35 \mathrm{ml}$./minute (Rubin, Henderson, Ommaya, Walker, and Rall, 1966; Cutler, Page, Galicich and Watters, 1968; Lorenzo, Page, and Watters, 1970). Figure 2 depicts the upper limit of the normal pressure-flow relationship as reported by Katzman and Hussey (1970). The slope of the line is a measure of resistance, and the upper limit is taken as $180 \mathrm{~mm}$ saline $/ \mathrm{ml} . /$ minute. Plotted $\stackrel{N}{\omega}$ on the same graph are the data reported by Cutler et $\vec{\omega}$ al. (1968). Using a different method they found the 윽 average resistance to be $132 \mathrm{~mm} / \mathrm{ml} . / \mathrm{min}$.

The validity of the preceding hypothesis depends on the following assumptions being correct:

1. Flow characteristics of saline and CSF are. $\overrightarrow{0}$ sufficiently similar to permit one to simulate in creased CSF flow by injecting saline.

2. Resistance to flow offered by the infusion tubing and needle, and by the normal spinal sub-

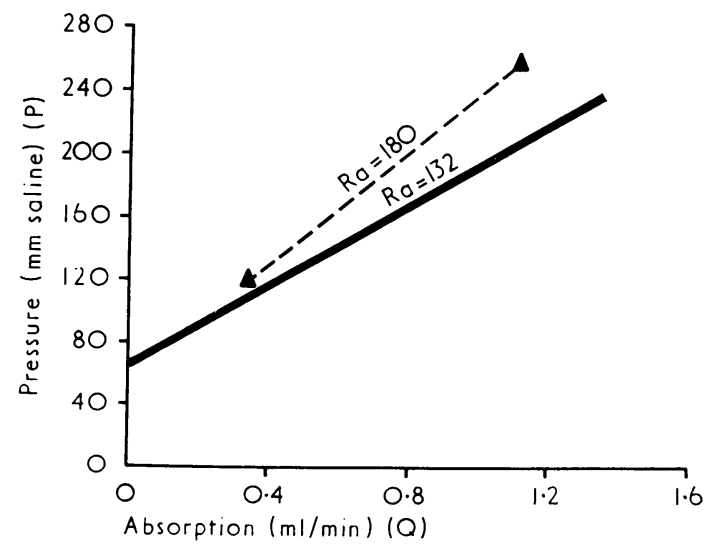

FIG. 2. Normal CSF pressure-flow relationship. The slope of the line $(\triangle P / \Delta Q)$ is a measure of apparent resistance ( $R a$ ) to CSF drainage. In normals the upper limit of $\mathrm{Ra}$ is taken as $180 \mathrm{~mm}$ saline/ml./min. $-=$ from Cutler et al. (1968). $\mathbf{\Delta}---\mathbf{\Delta}=$ from Katzman and Hussey (1970). 
arachnoid space is negligible. Resistance of the tubing used in the tests reported here is less than $1 \mathrm{~mm}$ saline $/ \mathrm{ml}$./minute. Resistance of the normal spinal subarachnoid space is unknown, but it is assumed to be small and sufficiently similar from patient to patient to allow one to ignore it.

3. Endogenous CSF is formed at a constant rate regardless of the CSF pressure. This has been found to be true for humans both normal (Rubin et al., 1966; Cutler et al., 1968) and abnormal (Lorenzo et al., 1970), at least up to $400 \mathrm{~mm}$ water, but not for the cat (Hochwald, Lux, Sahar, and Ransohoff, 1972).

4. The observed $\Delta \mathrm{P}$ is in fact equal to the actual change in pressure gradient (CSF pressure-dural sinus pressure). For this to be the case, dural sinus pressure must remain constant while the intracranial CSF pressure increases, which has been demonstrated to be true for cats and dogs (Weed and Flexner, 1933; Weed, 1935; Bering, 1958; Shulman, Yarnell, and Ransohoff, 1964; Shulman, 1965), as well as most adult humans so tested (author's unpublished data). But other reports leave little doubt that in some infants with hydrocephalus (Shulman and Ransohoff, 1965; Norrell, Wilson, Howieson, Megison, and Bertan, 1969), adults with subdural haematomas (Osterholm, 1970) and in hydrocephalic animals (Shulman et al., 1964; Sahar, Hochwald, and Ransohoff, 1970), the dural sinus pressure does indeed increase as the intracranial pressure increases. In this case $\mathrm{R}$, as measured by monitoring CSF pressure while changing $Q$ with the saline infusion, will be falsely high. Although a rise in dural sinus pressure does impede CSF drainage, forcing the steady-state CSF pressure yet higher, it does so by affecting the pressure gradient and not the resistance. And unless the dural sinus pressure is monitored during the ITSIT, one does not know in a given case if an impediment to CSF drainage is due to abnormal $\mathrm{R}$, to a rising dural sinus pressure, or to both. Consequently, resistance as measured in this study, without monitoring the dural sinus pressure, is referred to as 'apparent resistance' (Ra).

\section{RESULTS}

Of 36 tests attempted on 29 patients 35 were carried to completion. One test ended prematurely because the patient had radicular pain from needling of a rootlet. Complications were minor. About one-quarter of the patients had mild paresthaesiae of the lower extremities that resolved within an hour of the end of the test. One-third had some degree of typical postlumbar puncture headache, which resolved within one week. Neither aseptic nor pyogenic meningitis was encountered. (a)

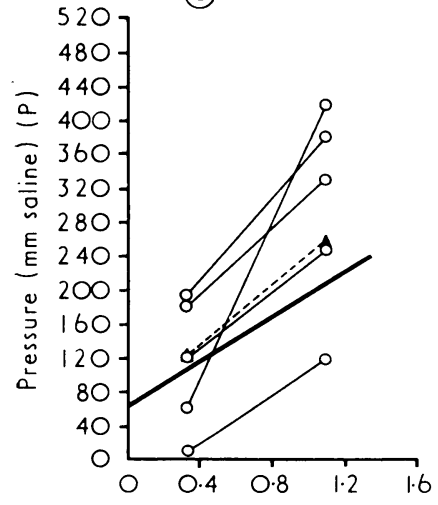

(b)

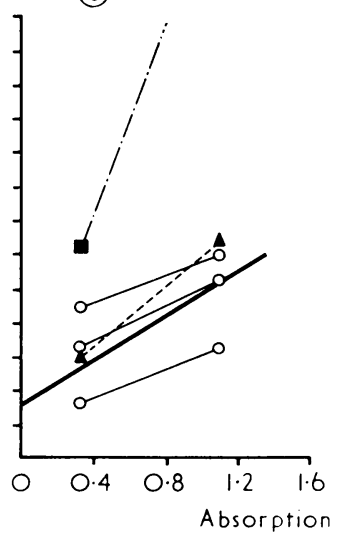

(c)

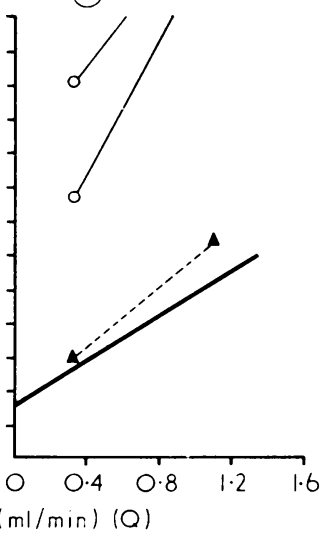

(d)

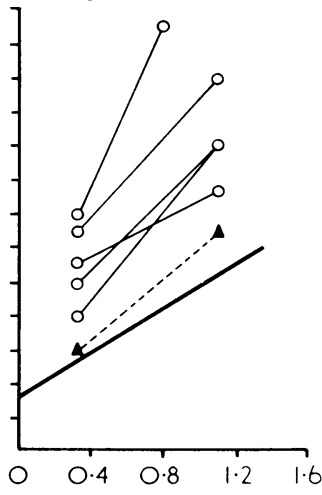

FIG. 3. CSF pressure-flow relationships in patients with diverse intracranial problems. (a) Hydrocephalus: two of the five are abnormal. (b) Post-traumatic encephalopathy (three cases-all normal) and active cryptococcal meningitis (one case-abnormal. Infusion stopped before steady-state was achieved). (c) Dural sinus obstruction: two cases, both abnormal. (d) Pseudotumor cerebri: four of five cases abnormal. The one case with normal Ra had had a subtemporal decompression two years before ITSIT. $-=$ from Cutler et al. (1968). $\mathbf{\Delta}--\mathbf{\Delta}=$ from Katzman and Hussey (1970). $\mathbf{\square}-\cdot-\mathbf{\square}=$ meningitis. $\bigcirc-\bigcirc=$ cases, except in (b) where $\mathrm{O}-\mathrm{O}=$ post-traumatic. 
TABLE 1

RESULTS OF INTRATHECAL SALINE INFUSION TEST

\begin{tabular}{lccc}
\hline Diagnosis & $\begin{array}{c}\text { Normal } \\
(\text { Ra }<180 \mathrm{~mm} \\
\text { saline/ml./min })\end{array}$ & $\begin{array}{c}\text { Abnormal } \\
(\text { Ra }>200 \mathrm{~mm} \\
\text { saline/ml./min })\end{array}$ & Total \\
\hline $\begin{array}{l}\text { Hydrocephalus } \\
\begin{array}{l}\text { Encephalopathy (cause } \\
\text { unknown) }\end{array}\end{array}$ & $2 *$ & 2 & $5 \dagger$ \\
$\begin{array}{l}\text { Brain tumour } \\
\text { 'Pseudotumor' }\end{array}$ & 3 & 2 & 5 \\
$\begin{array}{l}\text { Dural sinus obstruction } \\
\text { Post-traumatic encephalo- } \\
\text { pathy }\end{array}$ & 1 & 2 & $4 \ddagger$ \\
$\begin{array}{l}\text { Meningitis } \\
\text { Miscellaneous }\end{array}$ & 0 & 4 & 5 \\
\hline Totals & 3 & 2 & $3 \ddagger$ \\
\hline
\end{tabular}

* Shunt working and in place-one case.

$\dagger$ Result equivocal-one case.

$\ddagger$ Test invalid-one case.

$\S$ Sociopath with normal neurological examination and contrast studies.

TABLE 2

INTRATHECAL SALINE INFUSION TEST RESULTS COMPARED WITH ISOTOPE CISTERNOGRAM AND PNEUMOENCEPHALOGRAM IN 23 PATIENTS

\begin{tabular}{llll}
\hline Pneumoencephalogram & Isotope cisternogram \\
\cline { 4 - 5 } \cline { 4 - 5 } & normal abnormal normal abnormal \\
\hline
\end{tabular}

\begin{tabular}{llllll}
\hline ITSIT & & & & \\
$\begin{array}{l}\text { Normal } \\
\text { Abnormal (14) }\end{array}$ & $\begin{array}{l}0 \dagger \\
6\end{array}$ & 9 & 1 & 8 \\
\hline Totals & $(23)$ & 6 & 17 & 9 & 14 \\
\hline
\end{tabular}

* Includes only those patients with a valid ITSIT and a recent comparable PEG and isotope cisternogram.

$\dagger$ Apparent lack of concordance of normal test results is due to patient selection.

Table 1 summarizes the results from the entire series, and Table 2 compares the results of the ITSIT in 23 patients who also had pneumoencephalograms and isotope cisternograms suitable for comparison.

\section{DISCUSSION}

As expected, $\mathrm{Ra}$ was increased above normal in those conditions commonly considered as impeding CSF drainage, such as brain tumour, communicating hydrocephalus, and meningitis (Fig. 3). On the other hand, some results were unexpected. For example, the test was normal in a patient with communicating hydrocephalus and dementia. In another patient, whose neurological examination and contrast studies were normal, the test was abnormal. Such results provoke two questions: First, how reliable is this test? Second, what is the significance of an abnormal test?

This study indicates that the ITSIT is not $\stackrel{\overrightarrow{\vec{S}}}{\vec{a}}$ completely reliable because both false normal $\frac{0}{c}$ and false abnormal tests occur. A test will be 흠 falsely normal if all the saline is not infused into $\frac{\bar{\sigma}}{\overrightarrow{0}}$ the subarachnoid space or if fluid leaks from the $\varnothing$ subarachnoid space through a hole in the क meninges (Lundberg and West, 1965). Subse- $\overrightarrow{0}$ quent isotope cisternography helps to identify $\vec{\overrightarrow{ }}$ invalid tests, in that the isotope may loculate $\vec{\omega}$ subdurally or fail to rise normally into the head, as happened in seven of the 36 tests reported here. But it will not identify all occult leaks. Consequently a normal ITSIT should be given is little weight in the final decision-making process $\frac{\omega}{\omega}$ for or against shunt emplacement. A test will be

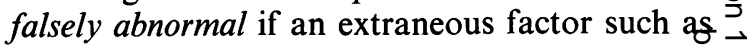
increased cerebral blood flow due to $\mathrm{CO}_{2}$ reten $\rightarrow$ tion independently increases $\mathrm{CSF}$ pressure Dozing may increase $\mathrm{PCO}_{2}$ sufficiently to rais $\overrightarrow{0}$ CSF pressure (Meyer, Gotham, Tazaki, and Gotoh, 1961). Both ketamine and halothane anaesthesia also increase cerebral blood flow and, in turn, the CSF pressure (McDowall, 1966; McDowall, Barker, and Jennett, 1966; Dawson, Michenfelder, and Theye, 1971; $\stackrel{\mathbb{D}}{\AA}$ Gardner, Olson, and Lichtiger, 1971). Finally, $\overrightarrow{\overrightarrow{\hat{O}}}$ CSF pressure can be driven to spuriously high 3 levels if a pot-bellied patient increases his central venous pressure by rolling even slightly prone. Nevertheless, because factors producing false abnormal tests are relatively easy to control, abnormal test results tend to be more reliable than normal ones.

What is the significance of increased resistance to CSF drainage? Often it appears to be related directly to symptoms, as for example in patients with hydrocephalus. But increased resistance to $\frac{7}{0}$ CSF drainage, and the attendant intracranial hypertension, can be asymptomatic, as was true $N$ for most patients with pseudotumor cerebri 0 (intracranial hypertension of unknown cause) or N partial occlusion of a dural sinus reported here. Therefore a cause and effect relationship be-e tween symptoms and increased resistance to $\mathrm{CSF}$ 
drainage cannot be assumed. To assess the significance of an abnormal ITSIT one must correlate it with the entire clinical picture. An abnormal infusion test alone is insufficient to justify placing a shunt.

For two patients among the 29 studied, the test provided decisive data: one patient with intracranial hypertension caused by partial occlusion of a lateral sinus, and another with active cryptococcal meningitis. Both patients had enormous increases in $\mathrm{Ra}$ to CSF drainage (Fig. 3b and c), neither had hydrocephalus, yet both probably benefited from shunt emplacement.

Table 2 compares the results of the pneumoencephalogram and isotope cisternogram with the ITSIT among each of 23 patients. The ITSIT revealed that 14 had impaired CSF drainage. Six of these 14 patients had normal pneumoencephalograms and they included four with pseudotumor cerebri, one with partial occlusion of a dural sinus, and one with a sociopathic personality but no neurological abnormality. Eight of the same 14 had normal isotope cisternograms and they included the four with pseudotumor cerebri, two with partial occlusion of a dural sinus, one with a thalamic glioblastoma, and the one sociopath. These data imply that impediment to CSF drainage sufficient to cause intracranial hypertension need not be associated with hydrocephalus; indeed such is usual for both patients and experimental animals with chronically elevated dural sinus pressure (Russell, 1949; Foley, 1955; Bradshaw, 1956; Kalbag and Woolf, 1967; Guthrie, Dunbar, and Karpell, 1970). Furthermore, they imply that unless the process that is increasing resistance to CSF drainage also grossly changes the CSF compartment, both pneumoencephalogram and isotope cisternogram remain normal. Finally, they imply that some cases of pseudotumor cerebri are caused by a process that impedes CSF drainage. Indirect evidence suggests two possible causes for the impediment. One is an occult lesion of the arachnoid villi, as suggested by the work of Hayes, McCombs, and Faherty (1971) with vitamin A-deficient calves that develop increased CSF pressure, presumably due to interference with CSF drainage by a fibrosis of the arachnoid villi. These calves do not develop hydrocephalus (K. C. Hayes, 1971, personal communication).
The second is a partial obstruction to the craniocerebral venous drainage system that is angiographically undetectable but nevertheless physiologically significant enough to elevate chronically the dural sinus pressure (Ray and Dunbar, 1951; Davidoff, 1956). These speculations could be sustained or refuted by adequate study in suitable cases of the morphology of the arachnoid villi and pressures within the dural venous sinuses.

\section{REFERENCES}

Bering, E. A., Jr. (1958). Problems of the dynamics of the cerebrospinal fluid with particular reference to the formation of cerebrospinal fluid and its relationship to cerebral metabolism. Clinical Neurosurgery, 5, 77-97.

Bradshaw, P. (1956). Benign intracranial hypertension. Journal of Neurology, Neurosurgery, and Psychiatry, 19, 2841.

Cutler, R. W. P., Page, L., Galicich, J., and Watters, G. V. (1968). Formation and absorption of cerebrospinal fluid in man. Brain, 91, 707-720.

Davidoff, L. M. (1956). Pseudotumor cerebri: benign intracranial hypertension. Neurology (Minneapolis), 6, 605-615.

Davson, H., Hollingsworth, G., and Segal, M. B. (1970). The mechanism of drainage of the cerebrospinal fluid. Brain, 93, 665-678.

Dawson, B., Michenfelder, J. D., and Theye, R. A. (1970). Effects of ketamine on canine cerebral blood flow and metabolism: modification by prior administration of thiopental. Anesthesia and Analgesia, 50, 443-447.

Foldes, F. F., and Arrowood, J. G. (1948). Changes in the cerebrospinal fluid pressure under the influence of continuous subarachnoid infusion of normal saline. Journal of Clinical Investigation, 27, 346-351.

Foley, J. (1955). Benign forms of intracranial hypertension. Brain, 78, 1-41.

Gardner, A. E., Olson, B. E., and Lichtiger, M. (1971). Cerebrospinal-fluid pressure during dissociative anesthesia with ketamine. Anesthesiology, 35, 226-228.

Guthrie, T. C., Dunbar, H. S., and Karpell, B. (1970). Ventricular size and chronic increased intracranial venous pressure in the dog. Journal of Neurosurgery, 33, 407-414.

Hayes, K. C., McCombs, H. L., and Faherty, T. P. (1971). The fine structure of vitamin A deficiency. 2. Arachnoid granulations and CSF pressure. Brain, 94, 213-224.

Hochwald, G. M., Lux, W. E., Jr., Sahar, A., and Ransohoff, J. (1972). Experimental hydrocephalus: changes in cerebrospinal fluid dynamics as a function of time. Archives of Neurology, 26, 120-129.

Hussey, F., Schanzer, B., and Katzman, R. (1970). A simple constant-infusion manometric test for measurement of CSF absorption. 2. Clinical studies. Neurology (Minneapolis), 20, 665-680.

Kalbag, R. M., and Woolf, A. L. (1967). Cerebral Venous Thrombosis. Oxford University Press: London.

Katzman, R., and Hussey, F. (1970). A simple constantinfusion manometric test for measurement of CSF absorption. 1. Rationale and method. Neurology (Minneapolis), 20, 534-544.

Lorenzo, A. V., Page, L. K., and Watters, G. V. (1970). Relationship between cerebrospinal fluid formation, absorption and pressure in human hydrocephalus. Brain, 93, 679-692. 
Lundberg, N., and West, K. A. (1965). Leakage as a source of error in measurement of the cerebrospinal fluid pressure by lumbar puncture. Acta Neurologica Scandinavica, 41, Supplement 13, 115-121.

McDowall, D. G. (1966). Cerebral haemodynamics and metabolism during general anaesthesia. Acta Anaesthesiologica Scandinavica, Supplement 25, 307-311.

McDowall, D. G., Barker, J., and Jennett, W. B. (1966) Cerebro-spinal fluid pressure measurements during anaesthesia. Anaesthesia, 21, 189-201.

Meyer, J. S., Gotham, J., Tazaki, Y., and Gotoh, F. (1961). Cardiorespiratory syndrome of extreme obesity with papilledema. Report of a fatal case with electroencephalographic, metabolic, and necropsy studies. Neurology (Minneapolis), 11, 950-958.

Norrell, H., Wilson, C., Howieson, J., Megison, L., and Bertan, V. (1969). Venous factors in infantile hydrocephalus. Journal of Neurosurgery, 31, 561-569.

Osterholm, J. L. (1970). Reaction of the cerebral venous sinus system to acute intracranial hypertension. Journal of Neurosurgery, 32, 654-659.

Pappenheimer, J. R., Heisey, S. R., Jordan, E. F., and Downer, J. de C. (1962). Perfusion of the cerebral ventricular system in unanesthetized goats. American Journal of Physiology, 203, 763-774.

Ray, B. S., and Dunbar, H. S. (1951). Thrombosis of the dural venous sinuses as a cause of 'pseudotumor cerebri'. Annals of Surgery, 134, 376-386.
Rubin, R. C., Henderson, E. S., Ommaya, A. K., Walker, M. D., and Rall, D. P. (1966). The production of cerebrospinal fluid in man and its modification by acetazolamide. Journal of Neurosurgery, 25, 430-436.

Russell, D. S. (1949). Dural sinus thrombosis and thrombophlebitis. In Observations on the Pathology of Hydrocephalus, pp. 86-94. Medical Research Council Special Report Series No. 265. H. M. Stationery Office: London.

Sahar, A., Hochwald, G. M., and Ransohoff, J. (1970). Cerebrospinal fluid and cranial sinus pressures. Archives of Neurology, 23, 413-418.

Shulman, K. (1965). Small artery and vein pressures in the subarachnoid space of the dog. Journal of Surgical Research, 5, 56-61.

Shulman, K., and Ransohoff, J. (1965). Sagittal sinus venous pressure in hydrocephalus. Journal of Neurosurgery, 23, 169-173.

Shulman, K., Yarnell, P., and Ransohoff, J. (1964). Dural $\vec{\circ}$ sinus pressure. In normal and hydrocephalic dogs. Archives of Neurology, 10, 575-580.

Weed, L. H. (1935). Forces concerned in the absorption of the cerebrospinal fluid. American Journal of Physiology, 114, 40-45.

Weed, L. H., and Flexner, L. B. (1933). The relations of the intracranial pressures. American Journal of Physiology, 105, 266-272. 